Revista de Derecho

\title{
Reflexiones jurídicas sobre el reconocimiento constitucional y penal del derecho indígena
}

\section{Legal reflections on the constitutional and criminal recognition of indigenous law}

\author{
Hugo Bayardo Santacruz Cruz \\ Docente-Investigador, \\ Pontificia Universidad Católica del Ecuador Sede Ibarra, Ecuador \\ hbsantacruz@hotmail.com \\ ORCID: 0000-0003-0950-8380
}

DOI: https://doi.org/10.32719/26312484.2020.34.6

Fecha de recepción: 19 de junio de 2018

Fecha de aceptación: 8 de enero de 2020 


\section{RESUMEN}

En los países latinoamericanos, la idea de pluralismo jurídico y el inicio de procesos encaminados a la búsqueda de la descolonización normativa presentan una lenta evolución. Gran parte de este lento desarrollo ha sido debido a la monopolización de la administración de justicia por parte del Estado, dado que el intervencionismo estatal ha desembocado en la penalización de las formas de control social de los pueblos indígenas que otrora eran permitidas. No obstante, en los últimos tiempos, el reconocimiento constitucional de la justicia indígena ha permitido que los pueblos indígenas puedan recrear y aplicar sus propias formas de control social respecto de conductas que la comunidad considera desaprobadas. Sin embargo, la injerencia estatal se resiste a dejar su intervencionismo y para ello utiliza legislación infraconstitucional que no ha presentado el mismo desarrollo de la Constitución, ya que en ella persisten rezagos de inferioridad que se creían superados. En este sentido, el presente artículo pretende plantear, por un lado, una visión descriptiva de los derechos que reconocen las constituciones de los países que integran la Comunidad Andina de Naciones y, por otro, la falta de sintonía que existe respecto de la legislación penal que a la fecha sigue, no solamente limitando sino criminalizando a la administración de la justicia indígena.

Palabras Clave: pueblos indígenas, pluralismo jurídico, estado de derecho, derecho y sociedad, derechos indígenas, sistemas jurídicos.

\section{ABSTRACT}

In Latin American countries, the idea of legal pluralism and the beginning of processes aimed at the search for normative decolonization have shown a slow evolution. Much of this slow development has been due to the monopolization of the administration of justice by the State, given that state intervention has resulted in the criminalization of the forms of social control of indigenous peoples that were once allowed. However, in recent times the constitutional recognition of indigenous justice has allowed indigenous peoples to recreate and apply their own forms of social control regarding behaviors that the community considers unapproved. State interference is reluctant to give up its interventionism and for that purpose it uses infra-constitutional legislation that has not presented the same constitutional development, since in these persistence the inferiority lags were believed to have been overcome. In this sense, this article intends to present, on the one hand, a descriptive vision of the rights recognized by the constitutions of the countries that make up the Community of Andean Nations and on the other, the lack of harmony that exists with respect to current legislation, not only limiting but criminalizing the administration of indigenous justice.

KEYWORDs: indigenous peoples, legal pluralism, rule of law, law and society, indigenous rights, legal systems. 


\section{INTRODUCCIÓN}

Ta ratificación del Convenio 169 por parte de los Estados andinos permitió que Lestos, reparando las injusticias pasadas y superando la idea decimonónica del Estado-nación, ${ }^{1}$ se sujeten a las premisas recogidas dentro de los instrumentos internacionales ${ }^{2}$ y reconozcan en sus Cartas políticas algunos derechos que son fundamentales para los pueblos indígenas y que, así mismo, eran distintos a los derechos colectivos tradicionalmente reconocidos a otros grupos humanos. ${ }^{3}$

Para esto, las reformas constitucionales llevadas en la década de 1990 por los distintos países andinos utilizan el verbo reconocer como una forma de señalar la preexistencia del derecho consuetudinario o indígena, como realidad sociocultural que ha sobrevivido y mantenido instituciones ancestrales en la cotidianidad de la vida colectiva. Por ello se enfatiza que las Constituciones nada inventan, solamente trasladan a su texto "hechos y situaciones propios de nuestra realidad que, en el pasado, si bien conocidos e interpretados antojadizamente por los que controlaban el poder político, no 'merecieron' constar en la Constitución". ${ }^{4}$

En la actualidad los distintos aspectos que las Constituciones han reconocido respecto de los derechos de los pueblos indígenas son susceptibles de ser agrupados dentro de tres grupos fundamentales de los cuales se derivan un conjunto de derechos que hacen que las comunas, comunidades, pueblos y nacionalidades indígenas surjan como entidades colectivas que tienen vida e instituciones propias. En este sentido, Raquel Yrigoyen señala que estos grupos de reconocimiento son: 1. el reconocimiento del carácter pluricultural de la Nación y el Estado, del que se desprende el reconocimiento de la pluralidad lingüística y jurídica; 2 . el reconocimiento del carácter de pueblos indígenas y la ampliación de sus derechos; y 3. el reconocimiento de la vigencia del derecho indígena o consuetudinario que otorga validez jurídica a las decisiones comunitarias y estatus de derecho público. ${ }^{5}$

1. Will Kymlicka, Ciudadanía multicultural. Una teoría liberal de los derechos de las minorías (Barcelona: Paidós, 1996), 18.

2. James Anaya, Los pueblos indigenas en el derecho internacional (Madrid: Ed. Trotta / Universidad Internacional de Andalucía, 2005), 235.

3. Hans-Jürgen Barndt y Rocío Valdivia, Normas, valores y procedimientos en la justicia comunitaria. Estudio cualitativo en comunidades indígenas y campesinas en Ecuador y Perú, Serie Justicia comunitaria en los Andes: Perú y Ecuador, vol. 2 (Lima: Instituto de Defensa Legal, 2007), 46.

4. Claudio Malo, Cultura e interculturalidad (Quito: Abya-Yala, 2002), 16.

5. Raquel Yrigoyen, "Reconocimiento constitucional del derecho indígena y la jurisdicción especial en los países andinos (Colombia, Perú, Bolivia, Ecuador)”, Revista Pena y Estado, n. ${ }^{\circ} 4$ (2000): 125, https://bit.ly/35YU5Be. 
Con estas referencias se puede apreciar que hay un claro reconocimiento de la pluriculturalidad y la multietnicidad de las sociedades que conforman los Estados andinos. ${ }^{6}$ Para el recordado Rodolfo Stavenhagen, este reconocimiento ha alterado el tradicional desconocimiento de los derechos de los pueblos indígenas en los textos constituciones, al punto de que hoy pude hablarse de la existencia de un constitucionalismo pluralista, en el que los pueblos indígenas han dejado de ser objetos de políticas para ser sujetos políticos, porque el Estado-nación naufragó y, en vez de este, surgió otro que, ante la diversidad étnica y cultural de su gente, reconoce "el derecho individual y colectivo a la propia identidad, y el reconocimiento del pluralismo jurídico".?

\section{LA POSITIVIZACIÓN DEL DERECHO INDÍGENA EN LA ZONA ANDINA}

\section{El caso de Colombia}

El caso de Colombia es significativo debido a que al mismo tiempo que se ratificaba el Convenio 169 de la OIT también se ultimaban los aspectos que habrían de reconocerse a los pueblos indígenas en la Constitución de $1991 .{ }^{8}$ Es así que Colombia, en esa atmósfera indígena, fue el primer país latinoamericano que elaboró un instrumento jurídico comprometido con la defensa de los derechos de los pueblos indígenas, a pesar de no contar con una población porcentualmente significativa, ya que estos eran cerca de $600.000^{9}$ indígenas, es decir, apenas representaban el $2 \%$ de la población del país, cosa que a decir de Frank Semper, facilitó para que la Asamblea Constituyente sin mayores inconveniente accediese a reconocerles algunos derechos, naciendo así un nuevo paradigma constitucional en esa nación. ${ }^{10}$

En efecto, con la Constitución colombiana de $1991^{11}$ se recogieron cinco grandes cambios que tendrían reveladoras repercusión en los pueblos indígenas: 1. el paso

\footnotetext{
6. María Ávila, "El Derecho Penal Indígena: entre la diversidad y los derechos humanos", American University International Law Review, vol. 28, n. ${ }^{\circ} 4$ (2013), disponible en https://bit.ly/2FYlWqC.

7. Rodolfo Stavenhagen, Los derechos humanos en las Américas: nuevos desafíos (Ciudad de México: Ed. Nuevo León, 2008), 30.

8. Carmen Becerra, "La jurisdicción especial indígena y el derecho penal en Colombia: entre el pluralismo jurídico y la autonomía relativa", revista El Otro Derecho, n. ${ }^{\circ} 35$ (2006): 220.

9. Rosembert Ariza, Pueblos indígenas de Colombia ante el Sistema Interamericano de Derechos Humanos. (Bogotá: Ed. Universidad del Rosario / Fundación Konrad Adenauer, 2013), 65.

10. Frank Semper, Los derechos de los pueblos indígenas de Colombia en la jurisprudencia de la Corte Constitucional (Uruguay: Fundación Konrad Adenauer, 2006), 762.

11. Colombia, Constitución Politica de Colombia, Gaceta Constitucional, n. ${ }^{\circ}$ 116, 20 de junio de 1991.
} 
de un Estado de Derecho a un Estado Social de Derecho; 2. el reconocimiento de un sujeto colectivo de derecho; 3. el paso de un Estado monocultural a uno multicultural y pluriétnico; 4. el trato distinto por la consideración de pueblos distintos (oficialidad de la lengua en sus territorios, jurisdicción, circunscripción electoral especial, entre otros); y 5 . la introducción del amparo o tutela de derechos fundamentales de los sujetos individuales como también de los sujetos colectivos. ${ }^{12}$

Dentro de los temas importantes, que hasta el día de hoy contempla la Constitución Política de Colombia de 1991, destacan los que tratan sobre el reconocimiento de la diversidad étnica, así como los distintos campos en que esta se puede expresar, tales como: la educación, cultura, territorio y ordenamiento territorial, participación política, participación económica y, por supuesto, la administración de justicia conforme a sus normas y procedimientos propios.

Cabe señalarse que la relevancia del reconocimiento de la diversidad étnica y cultural que hace la Constitución colombiana no reside solamente en que este se encuentre plasmado en la norma de normas, sino en el hecho de que sistemáticamente este haya sido registrado dentro del título de los principios fundamentales, puesto que así la diversidad étnica y cultural deben ser aplicadas con especial preferencia por parte de los operadores jurídicos. De ahí que varios artículos de la Carta Constitucional colombiana reconocen y protegen la diversidad étnica y cultural que se encuentra establecida con gran precisión tanto en el artículo 7 como en el artículo 8 que hacen alusión a la protección de las riquezas culturales y naturales de la nación. Así mismo el artículo10 señala el uso oficial de las lenguas y dialectos indígenas en sus territorios; el artículo 13 consagra el derecho a la igualdad y señala la obligación de adoptar medidas especiales, diferenciación positiva, para la atención de sectores discriminados o marginados como es el caso de los pueblos indígenas; el artículo 63 otorga el carácter de inalienables, imprescriptibles e inembargables de las tierras de resguardo; el artículo 68 garantiza el derecho de los grupos étnicos de recibir una enseñanza educativa que respete y desarrolle su identidad cultural; el artículo 70 señala que la cultura es fundamento de la nacionalidad; el artículo 72 establece la protección del patrimonio cultural de la nación; el artículo 96 confiere la doble nacionalidad para los indígenas de zonas de frontera; el artículo 171 implanta la participación de los indígenas en el Senado de la República; el art. 176 plantea la posibilidad de que los grupos étnicos y las minorías puedan participar en la Cámara de Representantes; los artículos 286 y 287 al igual que el artículo 329 mencionan que los territorios indígenas son entidades territoriales y que los resguardos son de propiedad colectiva y no

12. Esther Sánchez, "Reflexiones en torno a la jurisdicción especial indígena en Colombia", Revista IIDH, n. ${ }^{\circ}$ 41 (2005): 228. 
enajenable; los artículos 329 y 330 señalan que las entidades territoriales indígenas estarán gobernados por consejos y reglamentados según sus usos y costumbres; el artículo 357 da participación de los resguardos indígenas en los ingresos corrientes de la nación, y, finalmente, el artículo transitorio 56 que facultó al gobierno para dictar normas relacionadas con el funcionamiento de los territorios indígenas.

En cuanto al reconocimiento de la jurisdicción indígena, entendida como la facultad de administrar justicia que tienen las autoridades indígenas, la Constitución colombiana da nuevos bríos a las comunidades indígenas en su capítulo $\mathrm{V}$, dentro de las jurisdicciones especiales, y señala de manera expresa la facultad de administrar justicia que tienen las autoridades indígenas, al decir en su artículo 246 que estas ejercerán funciones jurisdiccionales dentro de su ámbito territorial, conforme a sus propias normas y procedimientos, en cuanto estos no sean contrarios a la Constitución y leyes colombianas. No obstante, pese a los avances que se han dado respecto de la tipificación de algunas conductas que atentan contra la diversidad cultural (delito de genocidio, la destrucción y apropiación de bienes culturales y lugares de culto, y el desplazamiento forzado), se sigue manteniendo una condición de inferioridad de los indígenas en lo que atañe a su imputación. Y es que en la actualidad el Código Penal colombiano, ${ }^{13}$ aunque no contemple los mismos términos la inimputabilidad del indígena que otrora lo hacía el Código Penal 1936, todavía dentro del catálogo de causas de exclusión de la culpabilidad señala como inimputable, al sujeto que al momento de ejecutar un injusto penal, por cuestiones de diversidad sociocultural no tuviere la capacidad de comprender su ilicitud o de determinarse de acuerdo con esa comprensión (artículo 33). En otras palabras, la norma penal, haciendo uso de otros términos, vuelve a colocar en una condición de inferioridad a los indígenas dado que estos son declarados nuevamente como inimputables debido a una incapacidad de comprensión derivada o atribuida a su cultura. Es de señalar que esta causal de inimputabilidad fue además malamente acompañada con la imposición de una medida de seguridad que consistía en la reintegración a su medio cultural (artículo 73), referencia que con posterioridad fue justamente declarada inexequible. ${ }^{14}$

Por otro lado, la vigencia de dos jurisdicciones simultaneas determinó que el Código de Procedimiento Penal de 2000, con sus posteriores modificaciones, exceptúe de la jurisdicción penal ordinaria los casos en los que la jurisdicción indígena haya tomado conocimiento a través de sus autoridades, las cuales solamente pueden ejercer sus funciones jurisdiccionales dentro su ámbito territorial y conforme a sus propias

13. Colombia, Código Penal, Diario Oficial, n. ${ }^{\circ}$ 44.097, 24 de julio de 2000.

14. Colombia, Corte Constitucional de Colombia, "Sentencia" C-370/02, en Juicio n. ${ }^{\circ}$ D-3751, 14 de mayo de 1992. 
normas y procedimientos, siempre y cuando estos no lleguen a ser contrarios a la Constitución y a las leyes.

\section{El caso de Perú}

En la misma línea del reconocimiento de los derechos de los pueblos indígenas, la Constitución Política de Perú ${ }^{15}$ de 1993 representa una ruptura con el ideario de Estado homogéneo, al punto que en su artículo 2.19 se abandona la definición monocultural precedente y apuntala el carácter pluriétnico y pluricultural de la nación, elevando a la categoría de derecho fundamental de las personas el derecho a la identidad étnica, de los cuales se desprende el derecho de usar su propio idioma ante cualquier autoridad mediante un intérprete.

Por su parte, el artículo 17 establece la obligatoriedad y gratuidad de la educación con el objeto de garantizar la erradicación del analfabetismo, fomentando la educación bilingüe e intercultural, respetando las diversas manifestaciones culturales y lingüísticas de un país que, según el artículo 48, tiene como idiomas oficiales el castellano y, en las zonas donde predominen, también lo son el quichua, el aimara y las demás lenguas aborígenes que se encuentran en un acelerado proceso de desaparición como indicadores de cohesión y producción cultural. ${ }^{16}$

El artículo 89 es una muestra de la superación del integracionismo político que pervivía en la Constitución de 1979 y que colocaba en rango de superioridad a la cultura hegemónica en detrimento de las comunidades campesinas y nativas que eran vistas como necesitadas del paternalismo oficial para conseguir su desarrollo cultural. Y es precisamente bajo la denominación de Comunidades Campesinas y Nativas que la constitución vigente, en el artículo 149 reconoce la jurisdicción indígena, facultando a las autoridades de esas comunidades a que, con el apoyo de las Rondas Campesinas, ejerzan dentro de sus territorios las funciones jurisdiccionales conforme a su derecho consuetudinario sin afectar los derechos fundamentales de las personas.

De esta manera el artículo 149, reconoce tanto el ejercicio de la jurisdicción indígena como la normatividad propia que tienen las comunidades. Se puede decir, por lo tanto, que el reconocimiento de la justicia en el Perú no se encuentra limitado respecto de algunas prácticas culturales minoritarias, sino que su alcance solamente estaría acotado por el respeto de los derechos humanos.

15. Perú, Constitución Política de Perú, promulgada, 29 de diciembre de 1993.

16. Hans-Jürgen Brandt y Rocío Valdivia, El tratamiento de conflictos. Un estudio de actas en 133 comunidades (Lima: Instituto de Defensa Legal, 2006), 44. 
En lo que respecta a la legislación penal, hay que reconocer que Perú es el único país que ha llevado al debate académico nuevas figuras penales que no existían y que son un referente futuro para los demás países de su entorno cultural. Así, pues, son novedosos los cambios que han existido en un país que, hasta no hace mucho tiempo, se encontraba vigente un Código Penal, el de 1924, que contenía normas que tipificaban el sometimiento y servidumbre de los indígenas, así como también contemplaba determinadas eximentes o atenuantes de las penas, basadas en la diferenciación racial que se tejía sobre los indígenas de la sierra y de la selva, a quienes se los tenía como semicivilizados o aborígenes salvajes. ${ }^{17}$

Con los nuevos derroteros que en el derecho internacional se comenzaban a atisbar, la legislación penal peruana fue orientándose hacia el respeto de los valores culturales derivados de la pluralidad étnica existente. Esto se dejó notar en los artículos 202 y 204 del Código penal de 1991 que establecen el delito de usurpación con su modalidad agravada cuando se trata de territorios de comunidades nativas o campesinas (MARENSI 2007, 53). Pero, además, se estableció en el artículo 15 la figura del error de comprensión culturalmente condicionado, con el cual, atendiendo a la incidencia de la cultura o costumbre, puede extinguir la responsabilidad penal o atenuarla. En el primero de los casos la responsabilidad penal se excluye cuando la persona influenciada por su cultura o costumbres comete un hecho punible sin poder comprender el carácter delictuoso de su acto o determinarse de acuerdo con esa comprensión. Por su parte, la responsabilidad penal puede ser atenuada cuando por igual razón, es decir por cuestiones de cultura o costumbres, esa posibilidad comprender únicamente se halla disminuida.

Por otro lado, pasando de las interpretaciones que se dan al error culturalmente condicionado -como lo han hecho los proyectos de reforma del Código penal de los años 2004 y 2009 que no han modificado la mencionada figura-, es preciso referir también que el Código Procesal Penal peruano en su artículo 18.3 hace referencia a los límites de la jurisdicción penal ordinaria, señalando que esta no es competente para conocer los hechos punibles surgidos en los territorios donde tienen jurisdicción las comunidades campesinas y nativas.

17. Ibíd., 54 . 


\section{El caso de Bolivia}

De forma similar a lo que habían establecido las Constituciones de Colombia y de Perú, Bolivia se embarcó en el horizonte del constitucionalismo pluralista. ${ }^{18}$ Es así como, luego de tres años de que este país ratificara el Convenio 169 de la OIT, se produjeron reformas constitucionales que intentaron, en alguna medida, incorporar la normativa internacional al plano nacional en lo que respecta a los derechos fundamentales de los pueblos indígenas.

Efectivamente con la Constitución Política del Estado de 1994, que vino a reformar a la Constitución de 1967, que al igual que sus predecesoras no reconocía el carácter heterogéneo de la estructura social boliviana, se da comienzo al reconocimiento de algunos derechos conforme al origen multiétnico y pluricultural ${ }^{19}$ que pasaba a tener el Estado boliviano y entre los cuales estaban: el carácter de sujetos políticos de las comunidades indígenas y campesinas; el derecho al control de sus instituciones sociales, políticas y culturales; el reconocimiento de diversas formas de participación, consulta y representación directa, así como también el reconocimiento del ejercicio de funciones de administración y aplicación de normas propias a través de las autoridades naturales de las comunidades indígenas cuando estas no contradigan a la Constitución y las leyes. ${ }^{20} \mathrm{Y}$ fueron precisamente las leyes secundarias las que limitarían enormemente la aplicación de los mandatos constitucionales, puesto que la fijación de los lineamientos básicos de la política indígena lo hicieron las leyes secundarias, lo cual condujo a que, pese al reconocimiento de la diversidad cultural, en la práctica exista una aplicación muy limitada.

Sin embargo, el 25 de enero de 2009, a través de referéndum se aprobó un nuevo texto constitucional que da un cambio paradigmático a la forma del Estado boliviano. En efecto, desde su promulgación ocurrida el 7 de febrero de 2009, se sientan las bases jurídicas para la construcción de una sociedad más incluyente que permita, en un plano de igualdad, la integración material de los pueblos indígenas a la estructura social, económica, política y cultural del Estado, generando una ruptura con la exclusión y marginación que históricamente ha acompañado, en todos esos ámbitos, a los miembros de los pueblos indígenas originarios.

18. Xavier Albó, "Justicia indígena en la Bolivia plurinacional”, en Justicia indígena, plurinacionalidad e interculturabilidad en Bolivia, ed. S. Santos y J. Exeni, 201-48 (La Paz: Fundación Rosa Luxemburg / Abya-Yala, 2012), 206.

19. Leonardo Tamburini, La jurisdicción indígena y las autonomías indigenas (La Paz: Fundación Rosa Luxemburg / Abya-Yala, 2012), 250.

20. Ibíd., 251. 
De hecho, con la actual Constitución del Estado Plurinacional de Bolivia ${ }^{21}$ se pasa de un Estado unitario, centralizado y monocultural a un Estado descentralizado y con autonomías, inspirado férreamente en la pluralidad y el pluralismo en sus distintos ámbitos dentro del proceso integrador del país. Con esta mención que se hace desde el primer artículo de la Constitución, se fundamenta la proclama que se declara en el preámbulo de la Constitución con relación a la refundación de Bolivia como Estado Plurinacional.

Así mismo, la Constitución de Bolivia de 2009 reconoce la persistencia del colonialismo, pero no del típico colonialismo constitucional que proclama la libre determinación de los pueblos de cara a la política exterior, sino de un colonialismo interno. Y es en este sentido que se plantea en términos frontales la descolonización del constitucionalismo (artículo 9), para consolidar las identidades plurinacionales.

En lo que respecta a la estructura del ordenamiento jurídico del Estado boliviano, desde el artículo 1 se proclama el pluralismo jurídico como fundamento esencial del nuevo modelo de Estado. En este contexto la Constitución expresamente menciona la igualdad jerárquica que existe entre la jurisdicción ordinaria y la jurisdicción indígena originaria campesina (artículo 179.I). Se especifica que la jurisdicción indígena deberá ser ejercida por las respectivas autoridades indígenas, aplicando los principios, valores culturales, normas y procedimientos propios. Así mismo el texto constitucional establece limitaciones no en forma de prohibiciones, sino más bien como afirmaciones, al señalar que la justicia indígena en la aplicación de sus normas y procedimientos propios respeta el derecho a la vida, a la defensa, y a los demás derechos y garantías establecidos constitucionalmente (artículo 190).

En lo que refiere a la competencia de la jurisdicción indígena se pude decir que, como consecuencia de las negociaciones políticas llevadas en el Congreso Nacional, esta se encuentra condicionada por la Ley de Deslinde Jurisdiccional de Bolivia que se dio a finales del año 2010.

En lo que respecta a la legislación penal hay que señalar que esta ha quedado rezagada frente a los avances plasmados en la Constitución boliviana. La lenta progresión del Código Penal boliviano respecto de la diversidad cultural resulta patente, y es evidente que, desde la derogación de la inimputabilidad del indígena, las sucesivas reformas que se han dado al Código Penal de $1972^{22}$ no han tratado de incorporar a la cultura o la costumbre expresamente como causa eximente responsabilidad penal, pues se ha dejado la tarea de adecuar el grado de reproche personal a las normas que

21. Bolivia, Constitución del Estado Plurinacional de Bolivia, promulgada en la ciudad de El Alto, 7 de febrero de 2009.

22. Bolivia, Código Penal. Elevado a rango de ley y modificado por la ley n. ${ }^{\circ} 1768,10$ de marzo de 1997. 
tratan sobre el error de prohibición (artículo $16 \mathrm{CP}$ ); la inimputabilidad (artículo 17); y la semi-imputabilidad (artículo $18 \mathrm{CP}$ ).

Además el artículo 40.4 del Código penal, respecto de las atenuantes generales de la responsabilidad penal, señala que esta puede darse cuando el sujeto activo del delito pudiera ser un indígena carente de instrucción y se pueda comprobar su ignorancia de la ley, con lo cual el límite de la culpabilidad se da valorando al sujeto concreto y a sus circunstancias, colocando la ignorancia solamente como un aspecto reductor del grado de culpabilidad, que se traduce en una pena conforme a los mínimos de la escala legales, por cuanto se estaría considerando una especie de error de prohibición vencible y mas no como un error de prohibición invencible (artículo $16 \mathrm{CP}$ ) que excluiría la responsabilidad penal.

Por su parte, el Código de Procedimiento Penal boliviano, en su artículo 28, establece que el ejercicio de la acción penal se extinguirá y no podrá ser objeto de un nuevo proceso penal ante la justicia ordinaria cuando los conflictos ocurridos dentro de una comunidad indígena hayan sido resueltos por las autoridades naturales indígenas conforme la justicia comunitaria sin afectar los derechos y garantías reconocidos en la Constitución. Con lo cual se mantienen bajo esta plausible consideración el respeto al principio non bis in ídem, así como también se deja en claro que las resoluciones hechas por la jurisdicción indígena solamente pueden ser revisadas cuando se verifique alguna violación a los derechos y garantías constitucionales del sancionado. Así mismo, dentro de las normas generales de la actividad procesal, se contempla la posibilidad de efectuar determinados actos procesales mediante el uso de otro idioma a través de intérpretes (artículos 10, 111-115 CPP); o atendiendo la diversidad cultural se prescribe que: en la etapa preparatoria, durante el juicio y antes de dictar sentencia habrá la asistencia de un perito especializado en cuestiones indígenas (artículo 391 CPP).

\section{El caso de Ecuador}

En esta misma línea cronológica, de conformación de nuevos paradigmas del reconocimiento de los derechos de los pueblos indígenas, ${ }^{23}$ se inscribe la Constitución ecuatoriana del año $2008,{ }^{24}$ la cual, frente al avance cada vez mayor del reconocimiento y protección de los derechos humanos en el derecho internacional, estableció en el artículo 424 que los tratados internacionales de derechos humanos al ser ratificados por

23. Ramiro Ávila, La (in)justicia penal en la democracia constitucional de derechos (Quito: Repositorio digital de la Universidad Andina Simón Bolívar, Sede Ecuador), 185.

24. Ecuador, Constitución de la República del Ecuador, Registro Oficial 449, 20 de octubre de 2008. 
el Estado prevalecerán sobre cualquier otra norma jurídica o acto del poder público y pasaran a tener la misma una jerarquía constitucional cuando los derechos reconocidos en estos instrumentos sean más favorables a los contenidos en la Constitución.

De esta manera el Convenio 169 de la OIT y los demás textos internacionales de derechos humanos, que habían sido ratificados por el Ecuador, pasaron a integrar el bloque de constitucional. ${ }^{25}$ Pero, además, acentuando el hecho de que estos, según el artículo 11.7 "no excluirá[n] los demás derechos derivados de la dignidad de las personas, comunidades, pueblos y nacionalidades, que sean necesarios para su pleno desenvolvimiento".

Bajo este nuevo horizonte, la Constitución ecuatoriana desarrolla las normas que guiarán la estructura del Estado que se declara como constitucional de derechos y justicia. Y que, en el caso de los pueblos y nacionalidades indígenas, estas normas se hallan encaminadas a proteger y garantizar el respeto y pleno ejercicio de la diversidad cultural, ya que, a la vez que reconocen a los miembros de los pueblos indígenas todos los derechos que tienen los demás ciudadanos, también se establece la prohibición de que estos sean sujetos de toda forma de discriminación (artículo 11.2). Además, con el objeto de materializar la diversidad cultural se reconoce al kichwa y el shuar como idiomas oficiales de relación intercultural (artículo 2), pero a su vez también se reconoce a los pueblos y nacionalidades indígenas la calidad de sujetos colectivos de derechos (artículo 10), con lo cual se deja por sentado que sobre los miembros de los pueblos indígenas recaen tanto los derechos individuales como los derechos que le son propios de un colectivo diferenciado.

Seguidamente la Constitución ecuatoriana, en el primer apartado de los derechos del buen vivir, se detiene a reconocer el derecho al agua como un derecho fundamental e irrenunciable (artículo 12), porque se entiende que de este depende la existencia y la continuidad de la vida humana. Sin embargo, la valoración de este derecho como tal no se desprende del derecho internacional de los derechos humanos, sino de las luchas sociales y ambientales que han protagonizado los pueblos indígenas, cuya cosmovisión está entrelazada de forma más compleja con la naturaleza o Pachamama, como ellos la denominan, y a la cual dotan de una existencia vital merecedora de protección y respeto, dado que la Pachamama es la que provee alimentos y regula la vida de todos los que habitamos en ella.

Es así cómo la filosofía indígena, pese a las injerencias externas, propugna que no hay que abusar de la Pachamama al punto de agotarla y destruirla, sino que hay que vivir en armonía con la naturaleza, aprovechando los recursos que esta ofrece en la medida necesaria y suficiente ${ }^{26}$ para que así la reproducción de la vida se siga dando.

25. Ecuador, Corte Constitucional del Ecuador, "Sentencia" 004-14-SCN-CC, en Juicio n ${ }^{\circ}$ 0072-14-CN, 6 de agosto de 2014.

26. Eugenio Zaffaroni, La Pachamama y el humano (Buenos Aires: Ed. Madres de Plaza de Mayo, 2011), 118. 
Y es precisamente acogiendo la sabiduría indígena que los legisladores ecuatorianos, en el artículo 71 de la Constitución, dotaron a la naturaleza del derecho a la restauración cuando aquella ha sido destruida. ${ }^{27}$

Además, la actual Constitución de Ecuador, avanzando lo que la anterior constitución del 1998 había logrado, en el artículo 171 se reconoce la diversidad cultural y las jurisdicciones de las comunidades, pueblos y nacionalidades indígenas, fundadas en sus tradiciones ancestrales y su derecho propio, dentro de su ámbito territorial y con garantía de la participación de la mujer indígena. Se señala, además, que las decisiones de la jurisdicción indígena deberán ser respetadas por las autoridades públicas que están en la obligación de no interferir en las decisiones de las autoridades indígenas que actúen en el ejercicio de la función jurisdiccional conferida.

De ahí que las resoluciones tomadas por las autoridades indígenas tienen el carácter de definitivas, siendo improcedente que otra autoridad pueda revisarlas o infringirlas, pues de hacerlo se estaría irrespetando el principio non bis in idem reconocido en el artículo 76.7 letra "i" de la Constitución ecuatoriana. Referencia que igualmente es recogida tanto en el artículo 344 letra "c" del Código Orgánico de la Función Judicial, como en el artículo 4.9 del Código Orgánico Integral Penal, el cual expresamente señala la prohibición de doble juzgamiento en los casos en que estos hayan sido resueltos por la jurisdicción indígena.

También es de apuntar que la Constitución ecuatoriana delegó al poder legislativo la creación de una ley de coordinación y cooperación entre las jurisdicciones indígena y ordinaria, lo que, hasta el día de hoy, es una tarea pendiente de la Asamblea Nacional, la cual no ha logrado pasar del debate a la promulgación de una ley que trate adecuadamente esta problemática.

Por su lado, la Corte Constitucional, por las atribuciones que le confiere la Constitución (artículo 436.7), ha sido el organismo que tímidamente ha tratado de dar respuesta a esta cuestión mediante un reducido número de sentencias que de forma clara han sentado un precedente en el país, no por lo positivo de sus apreciaciones, sino por las limitaciones que se han impuesto al ejercicio de la jurisdicción indígena. La Corte ha dejado por sentado que es facultad exclusiva de la justicia penal ordinaria el conocer, resolver y sancionar los casos que atenten contra la vida de toda persona, reduciendo así la jurisdicción indígena a delitos en los cuales no se encuentre el bien jurídico vida involucrado. ${ }^{28}$

27. Alberto Acosta, "Los derechos de la naturaleza. Una lectura sobre el derecho a la existencia", en La naturaleza con derechos. De la filosofía a la política, comps. Alberto Acosta y Esperanza Martínez (Quito: Abya-Yala, 2011), 341.

28. Ecuador, Corte Constitucional del Ecuador, "Sentencia" 113-14-SEP-CC, en Juicio n. ${ }^{\circ}$ 0731-10-EP, 30 de julio de 2014. 
En cuanto a la legislación penal, es necesario resaltar que en Ecuador se encuentra vigente codificación penal relativamente nueva, ${ }^{29}$ conocida como Código Orgánico Integral Penal (COIP). Esta codificación, que cuenta con más de diez reformas en su corta vida, tiene el distintivo de retomar una práctica antigua y abandonada,${ }^{30}$ como es el hecho de estructurar en un único cuerpo legal las regulaciones legislativas hechas en los ámbitos sustantivo, adjetivo y de ejecución penal. A decir de Zaffaroni, esta práctica legislativa es acertada, toda vez de que la historia da cuenta de que, al tratar separadamente estas tres disciplinas, su éxito se ha visto mermado porque un "código penal no puede responder a una orientación diferente de la procesal ni de la ejecutiva, so pena de quedar reducido a un acto de buena voluntad". ${ }^{31}$

Por otro lado, cabe mencionarse que integración doctrinal presente en este nuevo código tiene muy poca relación con el reconocimiento a la especificidad indígena, a pesar de que la Corte Constitucional ecuatoriana haya considerado que el COIP incorpora elementos interculturales que obligarían a los operadores jurídicos a "realizar verdaderos ejercicios hermenéuticos interculturales para no afectar los derechos reconocidos en la Constitución y en instrumentos internacionales de derechos humanos"; 32 lo cierto es que, a más de integrar las resoluciones de la jurisdicción indígena a efectos de configurar el principio non bis in ídem (artículo 5.9), solamente se vuelve hacer referencia a esta en la parte final del COIP en lo que son las disposiciones generales, mencionando ahí que las infracciones cometidas dentro de las comunidades, pueblos y nacionalidades indígenas se estará a lo que establezcan la Constitución, los tratados e instrumentos internacionales ratificados por el Estado, así como también lo que establezca el Código Orgánico de la Función Judicial y en las leyes respectivas.

Resulta claro que en la elaboración del COIP se desaprovechó una gran oportunidad de integrar desde una visión multicultural algunos preceptos que habrían atendido a los requerimientos que demanda la diversidad cultural y que la dogmática penal había señalado como valederos; tal es el caso del error de comprensión culturalmente condicionado, así como también circunstancias atenuantes que refieran a la cultura o costumbres de los pueblos indígenas.

29. Ecuador, Código Orgánico Integral penal, Registro Oficial 180, Suplemento, 10 de febrero de 2014.

30. Juan Vera, "Sobre la relación del derecho penal con el Derecho procesal penal", Revista Chilena de Derecho, vol. 44, n. ${ }^{\circ} 3$ (2017): 832, https://bit.ly/38cSVUf.

31. Eugenio Zaffaroni, Presentación del Anteproyecto de Código Orgánico de Garantías Penales del Ecuador (Quito: Ministerio de Justicia y Derechos Humanos, 2009), 18.

32. Ecuador, Corte Constitucional del Ecuador, "Sentencia" 004-14-SCN-CC, en Juicio n. ${ }^{\circ}$ 0072-14-CN, 6 de agosto de 2014. 
No obstante, conforme con las atribuciones conferidas constitucionalmente a la Asamblea Nacional en una reforma reciente, ${ }^{33}$ amplió las causas de inculpabilidad al incorporar en el artículo 35 el error de prohibición el cual puede ser vencible o invencible. En el primero de los casos se establece que no existiría responsabilidad penal, mientras que en el segundo al ser vencible se impondría una pena atenuada correspondiente a la pena mínima prevista en el tipo, reducida en un tercio.

\section{AVANCES Y RETROCESOS EN EL TRATAMIENTO PENAL DE LA DIVERSIDAD CULTURAL}

Hoy, al igual que ayer, los países andinos son un verdadero mosaico cultural donde convergen las más variadas culturas. Y es que en la actualidad el modelo idealizado de polis en la cual todos comparten ancestros, lenguaje y cultura comunes es una mera quimera. Pero pensar que en esa mixtura de culturas no surgirán conflictos es algo errado, ya que dentro de esa diversidad surgen divergencias que pueden llegar a enfrentar a minorías y mayorías. ${ }^{34}$

En este contexto un tema de inflexión ha sido, sin lugar a duda, el tratamiento penal que se debe dar a los miembros de los pueblos originarios, ya que permanentemente se ha pretendido que un sistema normativo de alcance nacional sea aplicado sin distingos ni excepciones a una realidad pluricultural. De hecho, bajo la vieja teoría de que la ignorancia de las leyes no excusa de su cumplimiento, ${ }^{35}$ la legislación penal tradicionalmente ha considerado irrelevante hacer distinción alguna cuando la persona infractora perteneciera a una cultura distinta de la hegemónica.

Para el derecho penal de los países andinos, en las primeras décadas del siglo XX, la cultura y la costumbre de los pueblos originarios no representaban elementos valorados dentro de una conducta típicamente relevante. Sin embargo, los tiempos cambian y las reivindicaciones obligan a repensar el derecho penal moderno y desarrollar diversos mecanismos o figuras penales que impidan la criminalización de prácticas culturales de determinados grupos étnicos.

En un principio, el criterio paternalista de los Estados desembocó en grandes deficiencias. Es así como inicialmente para evitar la criminalización las prácticas cul-

33. Ecuador, Ley orgánica reformatoria al Código Orgánico Integral Penal, Registro Oficial 107, Suplemento, 24 de diciembre de 2019, arts. 10 y 11.

34. Will Kymlcka, Ciudadanía multicultural. Una teoría liberal de los derechos de las minorías (Barcelona: Paidós, 1996), 14.

35. Francisco Muñoz Conde y Mercedes García Arán, Derecho penal. Parte general (Valencia: Tirant lo Blanch, 2010), 383. 
turales, que a los ojos de la cultura hegemónica resultaban ser contrarios a derecho, se recurrió a consideración a esos supuestos como formas de inimputabilidad, lo cual implicaba que se equiparaba a los indígenas con los menores de edad o con aquellos que padecían alguna enfermedad mental.

No obstante, el avance de la dogmática penal ha permitido que nuevas figuras superen las deficiencias de las existentes. Patente ejemplo de estas figuras es el error de prohibición culturalmente condicionado que viene a paliar las deficiencias técnicas de las normas anteriores, pero además proyecta una opción de respeto de la diversidad cultural y la identidad étnica de los ciudadanos.

En este sentido, el error culturalmente condicionado parte de las mismas premisas que conforman el error de prohibición, pero atribuyendo el error a cuestiones culturales que influyen decisivamente en el cometimiento de una conducta ilícita.

Dentro de las legislaciones andinas se ha podido demostrar que el Código penal peruano es el que más desarrollo dogmático integra, ya que es el único país que contempla dentro de su legislación penal la figura del error culturalmente condicionado. El resto de los países andinos únicamente han limitado y trasladado el tratamiento penal de los sujetos provenientes de los pueblos originarios a figuras penales que dejan ver el desinterés por integrar una perspectiva intercultural en su tratamiento punitivo. De hecho, cuando el ilícito es consecuencia de aspectos culturales o de costumbre, los operadores jurídicos han terminado eximiendo de responsabilidad penal aplicando figuras del error de prohibición o de inculpabilidad producto de trastorno mental, lo cual deja patente la inferioridad con que se trata a los que provienen de una cultura minoritaria distinta de la dominante.

El caso peruano puede considerarse distinto, dado que su legislación penal contempla el error de prohibición culturalmente condicionado con distintas variantes. Se señala que el error de prohibición culturalmente condicionado no solamente se presenta cuando a un sujeto, por su cultura y costumbres, le resulta imposible comprender la ilicitud de su hecho, sino también cuando por iguales razones esa posibilidad de comprensión se encuentra disminuida. De este modo el Código penal peruano permite eximir o atenuar la pena en función de la comprensión que el sujeto tenga respecto del hecho punible. Esto quiere decir que si un sujeto, por cuestiones culturales o de costumbre, se encuentra en una imposibilidad absoluta de comprensión, será eximido de pena, mientras que si se encuentra su capacidad de comprensión tan solo disminuida la pena le puede ser atenuada.

Es de señalar que, si bien la legislación penal peruana representa un gran avance en el tratamiento de la responsabilidad penal de los indígenas, su análisis no ha estado exento de críticas. Se acusa el hecho de que interpretarse de esa manera se estaría aplicando el error culturalmente condicionado conforme el grado de aculturización de los indígenas, lo que sería una vuelta a los modelos unilineales de desarrollo. Por ello se 
propone que la interpretación del artículo 15 se haga sin perspectivas asimilacionistas, lo cual sería entendiendo que el mencionado artículo contiene, por un lado, el error de comprensión culturalmente condicionado, y, por el otro, la conciencia disidente. ${ }^{36}$

En el caso de error de comprensión culturalmente condicionado estaría excluida la culpabilidad, mientras que en el caso de conciencia disidente procedería una disminución de la culpabilidad y por ende de la sanción penal. La justificación para esta distinción entre error y conciencia disidente estaría dada por la presencia de los términos cultura y costumbre que contiene el mencionado artículo. Así lo considera Luis Francia, dado que ambos términos entrañan cuestiones diferentes que son precisamente las que configurarían una u otra figura respecto del hecho punible. Subraya que el término cultura señalaría la imposibilidad de comprensión de la norma penal, mientras que el término costumbre estaría vinculado a desobediencia de la norma penal. ${ }^{37}$

\section{CONCLUSIONES}

El reconocimiento de la pluralidad jurídica, que por siglos estuvo presente a la sombra del ordenamiento jurídico, hoy permite vislumbrar algunos elementos comunes que delimitan el contenido y alcance de la jurisdicción indígena en el ordenamiento constitucional. De hecho, siguiendo el criterio de la Corte Constitucional colombiana, puede señalarse que el primero de ellos se refiere a la posibilidad de que existan autoridades judiciales propias de los pueblos indígenas; el segundo se encuentra relacionado con la potestad de los pueblos indígenas de establecer normas y procedimientos propios; el tercero claramente direccionado a someter la jurisdicción y normas de estos pueblos a la Constitución; y el cuarto, y último elemento, enfocado en la competencia del legislador para señalar la forma de coordinación de la jurisdicción indígena con el sistema justicia ordinario.

Con la positivización de estos elementos se puede apreciar que de forma clara se está reconociendo, por un lado, la facultad no solo jurisdiccional sino legislativa que tienen los pueblos indígenas, a través de sus autoridades, para aplicar y sobre todo crear o adaptar sus normas y procedimientos propios, cuestión que en definitiva conforman el núcleo de autonomía otorgado a las comunidades indígenas. Por otro lado, se está haciendo referencia tanto a los mecanismos de integración entre los diferentes sistemas de justicia indígena con el sistema judicial ordinario como también a la po-

36. Luis Francia, "Pluralidad cultural y Derecho penal", PUCP. Revista de la Facultad de Derecho, n. 47 (1993): 510.

37. Ibíd., 512 . 
testad que tienen los legisladores para establecer los criterios de coordinación entre las distintas jurisdicciones.

De lo manifestado, resulta evidente que en el ámbito constitucional existe un notable avance en el reconocimiento de la jurisdicción indígena. No obstante, es de destacar que este avance no tiene reflejo o la misma notoriedad en el ámbito penal, dado que en esta rama del ordenamiento jurídico la perspectiva intercultural ha terminado por reverdecer la inferioridad que otrora se atribuía a los integrantes de los pueblos indígenas.

Se han exteriorizado en la zona andina los operadores jurídicos al tratar conflictos de naturaleza penal que no han sido tratados por la jurisdicción indígena, y que presentan visos de haber sido cometidos por cuestiones culturales o de costumbres; lo que hacen es aplicar figuras penales que excluyan o atenúen su responsabilidad penal. Para ello recurren, como en el caso boliviano, al uso de atenuantes que se aplican exclusivamente para indígenas carente de instrucción y se pueda comprobar su ignorancia de la ley. Otros en cambio lo hacen mediante error de prohibición y, por supuesto, la inimputabilidad por cuestiones de diversidad sociocultural, lo cual pone al mismo nivel de aquellos que presentan una incapacidad mental.

Para finalizar es de destacar la legislación peruana que es la única que contempla el error culturalmente condicionado, el cual, como se ha señalado, proyecta una postura de respeto a la diversidad cultural y la identidad étnica de los miembros de los pueblos indígenas.

\section{BIBLIOGRAFÍA}

Acosta, Alberto. "Los derechos de la naturalza. Una lectura sobre el derecho a la existencia". En La naturaleza con derechos. De la filosofia a la política, compilado por Alberto Acosta y Esperanza Martínez, 317-67. Quito: Abya-Yala, 2011.

Albó, Xavier. “Justicia indígena en la Bolivia plurinacional”. En Justicia indígena, plurinacionalidad e interculturabilidad en Bolivia, editado por S. Santos y J. Exeni, 201-48. La Paz: Fundación Rosa Luxemburg / Abya-Yala, 2012.

Anaya, James. Los pueblos indigenas en el derecho internacional. 2a. ed. Madrid: Trotta / Universidad Internacional de Andalucía, 2005.

Ariza, Rosembert. Pueblos indigenas de Colombia ante el Sistema Interamericano de Derechos Humanos. Bogotá: Universidad del Rosario / Fundación Konrad Adenauer, 2013.

Ávila, María. "El Derecho Penal Indígena: entre la diversidad y los derechos humanos". American University International Law Review, vol. 28, n. ${ }^{\circ} 4$ (2013): 943-74. Disponible en https://bit.ly/2FYlWqC. 
Ávila, Ramiro. La (in)justicia penal en la democracia constitucional de derechos. Repositorio digital de la Universidad Andina Simón Bolívar, Sede Ecuador, 2010. Disponible en https://bit.ly/370pLrr.

Becerra, Carmen. "La jurisdicción especial indígena y el derecho penal en Colombia: entre el pluralismo jurídico y la autonomía relativa”. El Otro Derecho, n. 35 (2006): 213-36.

Bolivia. Código Penal. Elevado a rango de ley y modificado por la ley n. ${ }^{\circ} 1768,10$ de marzo de 1997.

-. Constitución del Estado Plurinacional de Bolivia. Promulgada en la ciudad de El Alto, 7 de febrero de 2009.

Brandt, Hans-Jürgen, y Rocío Valdivia. El tratamiento de conflictos. Un estudio de actas en 133 comunidades. Serie Justicia comunitaria en los Andes: Perú y Ecuador. Vol. 1. Lima: Instituto de Defensa Legal, 2006.

- Normas, valores y procedimientos en la justicia comunitaria. Estudio cualitativo en comunidades indígenas y campesinas en Ecuador y Perú. Serie Justicia comunitaria en los Andes: Perú y Ecuador. Vol. 2. Lima: Instituto de Defensa Legal, 2007.

Colombia. Código Penal, Diario Oficial n. ${ }^{\circ}$ 44.097, 24 de julio de 2000.

- Constitución Política de Colombia. Gaceta Constitucional n. ${ }^{\circ}$ 116, 20 de junio de 1991.

-. Corte Constitucional de Colombia. "Sentencia" C-370/02. En Juicio n. ${ }^{\circ}$ D-3751, 14 de mayo de 2002.

Ecuador. Código Orgánico Integral Penal. Registro Oficial 180, Suplemento, 14 de agosto de 2014.

-. Constitución de la República del Ecuador. Registro Oficial 449, 20 de octubre de 2008.

- Corte Constitucional del Ecuador. "Sentencia" 004-14-SCN-CC. En Juicio n. ${ }^{\circ}$ 0072-14CN, 6 de agosto de 2014.

-. Corte Constitucional del Ecuador. "Sentencia” 113-14-SEP-CC. En Juicio n. ${ }^{\circ}$ 0731-10-EP, 30 de julio de 2014.

Francia, Luis. "Pluralidad cultural y Derecho penal". Derecho PUCP, n. ${ }^{\circ} 4$ (1993): 493-523.

Hurtado, José. "Derecho penal y diferencias culturales: perspectiva general sobre la situación en el Perú". En Sistema de control penal y diferencias culturales. Anuario de Derecho Penal 2010, dirigido por José Hurtado, 113-72. Lima: Pontificia Universidad Católica del Perú, 2012.

Kymlicka, Will. Ciudadanía multicultural. Una teoría liberal de los derechos de las minorías. Barcelona: Paidós, 1996.

Malo, Claudio. "Cultura e interculturalidad”. En Justicia indígena. Aportes para un debate, compilado por Judith Salgado, 15-22. Quito: Abya-Yala, 2002.

Muñoz, Francisco, y Mercedes García. Derecho Penal. Parte General. Valencia: Tirant lo Blanch, 2010.

Perú. Código Penal, Decreto Legislativo n. ${ }^{\circ}$ 635, 3 de abril de 1991.

—. Constitución Política de Perú. Promulgada, 29 de diciembre de 1993. 
Sánchez, Esther. "Reflexiones en torno a la jurisdicción especial indígena en Colombia". Revista IIDH, n. ${ }^{\circ}$ 41, edición especial sobre derecho indígena (enero-junio 2005): 225-51. Disponible en http://www.iidh.ed.cr/Publicaciones/Revista41/Derecho\%20indigena.pdf.

Semper, Frank. "Los derechos de los pueblos indígenas de Colombia en la jurisprudencia de la Corte Constitucional". En Anuario de Derecho Constitucional Latinoamericano, tomo II, editado por Jan Woischnik, 761-78. Uruguay: Fundación Konrad Adenauer, 2006.

Stavenhagen, Rodolfo. "Los derechos Humanos en las Américas: nuevos desafíos". En Los Derechos Humanos en las Sociedades Contemporáneas, coordinado por Gloria Ramírez, 21-38. Ciudad de México: Ed. Nuevo León, 2008.

Tamburini, Leonardo. "La jurisdicción indígena y las autonomías indígenas”. En Justicia indígena, plurinacionalidad e interculturabilidad en Bolivia, editado por S. Santos y J. Exeni, 249-70. La Paz: Fundación Rosa Luxemburg / Abya-Yala, 2012.

Vera, Juan. "Sobre la relación del derecho penal con el Derecho procesal penal". Revista Chilena de Derecho. Vol. 44, n. ${ }^{\circ} 3$ (2017): 832-55, https://bit.ly/38cSVUf.

Yrigoyen, Raquel. "Reconocimiento constitucional del derecho indígena y la jurisdicción especial en los países andinos (Colombia, Perú, Bolivia, Ecuador)". Revista Pena y Estado, n. ${ }^{\circ}$ 4. Buenos Aires: Ed. El Puerto, 2000. Disponible en https://bit.ly/35YU5Be.

Zaffaroni, Eugenio. La Pachamama y el humano. Buenos Aires: Ed. Madres de Plaza de Mayo, 2011.

—. "Presentación del Anteproyecto de Código Orgánico de Garantías Penales del Ecuador". En Anteproyecto de Código Organico de Garantías Penales. La constitucionalización del derecho, coordinado por Ramiro Ávila, 11-9. Quito: Ministerio de Justicia y Derechos Humanos, 2009. 